\title{
Correlation of ultrasonographic estimated fetal weight with actual birth weight in a tertiary hospital in Lagos, Nigeria.
}

\author{
Cletus Uche Eze, Livinus Chibuzo Abonyi, Jerome Njoku, Udo Okorie, Olayinka Owonifari
}

University of Lagos, radiation biology, radiotherapy, radiodiagnosis and radiography

\begin{abstract}
Background: Sonographic fetal weight estimation is an important component of antenatal care.

Aim: To sonographically estimate fetal weight at term and to compare estimated with actual birth weights to determine the validity of estimated fetal weights.

Subjects and methods: In the prospective study, a convenience sample of 282 women was recruited. Ethical approval and informed consent of patients were obtained. An experienced sonographer estimated fetal weights by measuring BPD, HC, AC and FL using a scanner with Hadlock 3 weight estimation model. Actual birth weights were measured with a Crown weighing scale by a midwife. Data was analyzed with SPSS software version 17.0 while descriptive and inferential statistics were used to interpret results. Results were tested at error level set at $\mathrm{p} \leq 0.05$.

Results: Mean estimated and actual birth weights were 3378 $\pm 40 \mathrm{~g}$ and $3393 \pm 60 \mathrm{~g}$ respectively. Difference between the two means was not significant. Eleven percent of fetuses were sonographically estimated to be microsomic while $14.5 \%$ were microsomic at birth; $12.1 \%$ were sonographically estimated to be macrosomic but $15.2 \%$ were macrosomic at birth. Most macrosomic fetuses were delivered through cesarean section(CS) and fetal weights increased with maternal age and parity. Conclusion: Sonographically estimated fetal weight using Hadlock 3 weight estimation model without validation correlated positively with actual birth weight in a Nigerian population.
\end{abstract}

Keywords: Estimated fetal weight; actual birth weight; sonography; Nigeria.

DOI: http://dx.doi.org/10.4314/ahs.v15i4.9

Cite as: Eqe CU, Abonyi LC, Njoku J, Okorie U, Owonifari O. Correlation of ultrasonographic estimated fetal weight with actual birth weight in a tertiary hospital in Lagos, Nigeria. Afri Health Sci. 2015;15(4):1112-22. http:/ / dx.doi.org/10.4314/abs. v15i4.9

\section{Introduction}

Maternal and infant mortality is a major public health issue in Nigeria. ${ }^{1}$ The country was reported to have the second highest maternal and infant mortality rates in the world. ${ }^{2}$ Antenatal care reduces both maternal and infant morbidity and mortality and prenatal fetal weight estimation is known to be an important component of standard antenatal care. ${ }^{3}$ Fetal weight is one of the determinants of outcome of pregnancies and also a major determinant of infant mortality in the first year of life. ${ }^{3}$ Pre-natal fetal weight estimation, as an impor-

\section{Corresponding author: \\ Cletus Uche Eze, University of Lagos, radiation biology, radiotherapy, radiodiagnosis and radiography Email: ceze@unilag.edu.ng / cueze@cmul.edu.ng.}

tant aspect of routine obstetric care, helps clinicians to prepare for anticipated preterm deliveries, and to settle for the optimal delivery route. ${ }^{4}$ Pre-natal fetal weight prediction is helpful, for instance, in determining intra-uterine growth restriction (IUGR) which is necessary in planning for peri-natal management of such babies. ${ }^{4,5}$ Maternal risks associated with the delivery of an excessively large fetus include birth canal and pelvic floor injuries, as well as postpartum hemorrhage. ${ }^{6}$ The incidence of cephalopelvic disproportion (CPD) is also higher among macrosomic fetuses compared with microsomic ones with such excessive weight fetuses often requiring 'operative vaginal delivery or cesarean delivery. ${ }^{6}$

Infant mortality rates (pre and peri-natal) are more sensitive to fetal birth weights than to their gestational ages and the delivery of macrosomic fetuses is a major obstetric challenge with any attempt at vaginal delivery often requiring 'considered attention' by an experienced 
obstetrician and 'preparedness for operative delivery, shoulder dystocia and newborn asphyxia'.,8 Both low birth weight and excessive fetal weight are associated with an increased risk of newborn complications during labor and the puerperium. ${ }^{4}$ Perinatal complications associated with low birth weight include either preterm delivery or intrauterine growth restriction (IUGR), or both while complications associated with macrosomia include shoulder dystocia, brachial plexus injuries, bony injuries, and intrapartum asphyxia. ${ }^{9,10}$ It has been suggested by some investigators that accurate prediction of fetal weight is useful to clinicians not just in the management of labour but also in reducing complications usually associated with microsomia thereby reducing maternal and peri-natal morbidity and mortality. ${ }^{4,10}$

The use of ultrasonography for the pre-natal estimation of fetal weight is very popular. Ultrasound was hailed by some investigators as a valuable imaging modality in determining how 'large' the fetus is and also useful in excluding fetal anomalies among 'small for date' fetuses. ${ }^{11}$ Sonographic fetal weight could be predicted by measuring one fetal parameter such as the Biparietal diameter (BPD), Abdominal Circumference (AC), Femur Length (FL), and Head Circumference (HC) or by a combination of several of these fetal parameters. ${ }^{12}$ Several investigators believe, however, that a combination of several fetal parameters yields more accurate estimates of fetal weights. ${ }^{12,13,14}$

Following the use of sonography in the prediction of pre-natal fetal weight, the modality was immediately touted as being superior to various clinical models of fetal weight estimation ( most of the very well-known clinical models such as the tactile method, evaluation of clinical risk factor and the use of birth weight estimation formulae are associated with considerable variation). ${ }^{4,15,16}$ The advantage of sonographically estimated fetal weight over clinical methods was suggested to be due to the fact that sonographic fetal weight estimation relies on objective intra-uterine linear and /or planar measurement of fetal parameters, thereby eliminating subjectivity associated with clinical methods. ${ }^{17}$ Many investigators, however, view sonographic fetal weight prediction as complicated, laborious and have also suggested that the modality is adversely affected by maternal characteristics including age and weight, anteriorly located placentae and oligohydramnious and racial factors. ${ }^{18,19,20,21}$ Racial variation in sonographic estimation of fetal weight, for instance, is high enough that some investigators have suggested that 'sonographic fetal weight prediction models derived from one ethnic population when applied in another locality, without the validation of its clinical applicability, might result in wrong estimations'. ${ }^{20}$

Several studies have been carried out in America, Europe and Asia which compared sonographically estimated fetal weights (EFWs) with actual birth weights (ABWs) of fetuses in order to determine the accuracy of EFWs in their respective population..$^{22,23,24}$ All ultrasound scanners in use in Nigeria are imported from developed countries in America, Europe and Asia with their weight estimation models undoubtedly derived with data from those populations. To the best of our knowledge, data on the weight of Nigerian fetuses are sparse, and data on the correlation of sonographically estimated fetal weights in the country with actual birth weight in order to establish the validity of estimation models in the country is even sparser. This study was, therefore, carried out to sonographically estimate fetal weights in a population of Nigerian pregnant women in a busy tertiary hospital in Lagos metropolis. It also compared sonographically EFWs with ABWs in order to determine the validity of Hadlock 3 fetal weight estimation algorithm in Lagos metropolis.

\section{Subjects and methods}

The study was carried out using a cross sectional research design between July, 2012 and June, 2013.

\section{Ethical approval/informed consent}

The study design was approved by the hospital's ethical committee on research involving human subjects before the study began. Informed consent of each participant was also obtained before recruitment.

\section{Target population}

The target population was pregnant women booked for antenatal care and for subsequent delivery at term at EKO hospital PLC, Lagos, and who were required to undergo ultrasound scan examination at each trimester of pregnancy in the ultrasound center of the hospital.

\section{Subject inclusion}

Only women with singleton pregnancies uncomplicated by maternal or fetal diseases were recruited.

\section{Sampling technique / sample size}

Convenience sampling technique was used to select a 
sample of 282 subjects who met the inclusion criteria for the study.

\section{Equipment used}

All sonographic examinations were carried out with a Sichuan-Xukang ultrasound scanner, Model XK/21355LCD manufactured in 2011 by Sichuan-Xukang Medical Electrical Appliances Co. Ltd., China. The scanner has a $3.5 \mathrm{MHz}$ convex transducer. The scanner has Hadlock 3 fetal weight estimation algorithm. Actual birth weights (ABWs) were measured with the 'Crown' neonatal weighing scale manufactured in 2008 by Ramon Surgical Co. Ltd., New Delhi, India. The weighing scale was corrected for zero error prior to use to enhance reliability of measurement.

\section{Data collection}

Demographic data such as age, menstrual history and parity were obtained from patients and recorded in a data capture sheet.

\section{Sonographic data}

An experienced sonographer who had used the scanner consistently for more than a year performed all sonographic examinations. Before the study commenced, fetal parameters such as BPD, HC, AC and FL were measured repeatedly by the sonographer and another slightly more experienced sonographer in 30 subjects randomly selected from the sample. The two sonographers were blinded to each other's measurements. The data they generated in this pilot survey were used to determine the intra and inter rater reliability of sonographic measurements. The mean in the two sonographers' replicate measurements were calculated. The differences within each sonographer's mean measurements and between the two sonographers' mean measurements were com- pared. Two tailed t test showed that differences within and between means were not statistically significant ( $p>0.05)$. It was then assumed that observer errors of measurement would not significantly affect results of the study.

\section{Scanning technique}

The scan-delivery interval (SDI) adopted for the study was one week. ${ }^{23}$ Before a patient was positioned for scanning, the procedure was explained to her. A female nurse assistant acted as a chaperon throughout the study period as par the hospital's protocol for obstetric sonography. Each patient was directed to lie supine on the examination couch with the abdomen exposed from the xiphisternum to the pubic symphysis. ${ }^{5}$ Ultrasonic gel was then liberally applied to the exposed portion of the abdomen.

\section{BPD And HC measurement}

For BPD measurement, a transverse scan image of the fetal skull showing a midline echo due to reflection by the falx cerebri (this is the linear echo that runs from the frontal to the occipital fold of the fetal head) was captured. This image also showed the thalamus and the cavum septum pellucidum in the midline. ${ }^{5,7,11,26}$ To measure BPD, the cursor was placed at the outer aspect of the near side echoes close to the transducer and then moved with the trackball to the inner aspect of the far side echo. ${ }^{5}$ The distance measured at right angles to the midline echoes from the outer to inner aspects of the two temporo-parietal bones is the BPD. ${ }^{7,26}$ The head circumference $(\mathrm{HC})$ was measured from the same image from which BPD was measured by placing the cursor at any point in the fetal skull and then using the trackball to trace its (the fetal skull's) perimeter. ${ }^{7}$ Measurement of BPD and $\mathrm{HC}$ are shown in figure 1. 

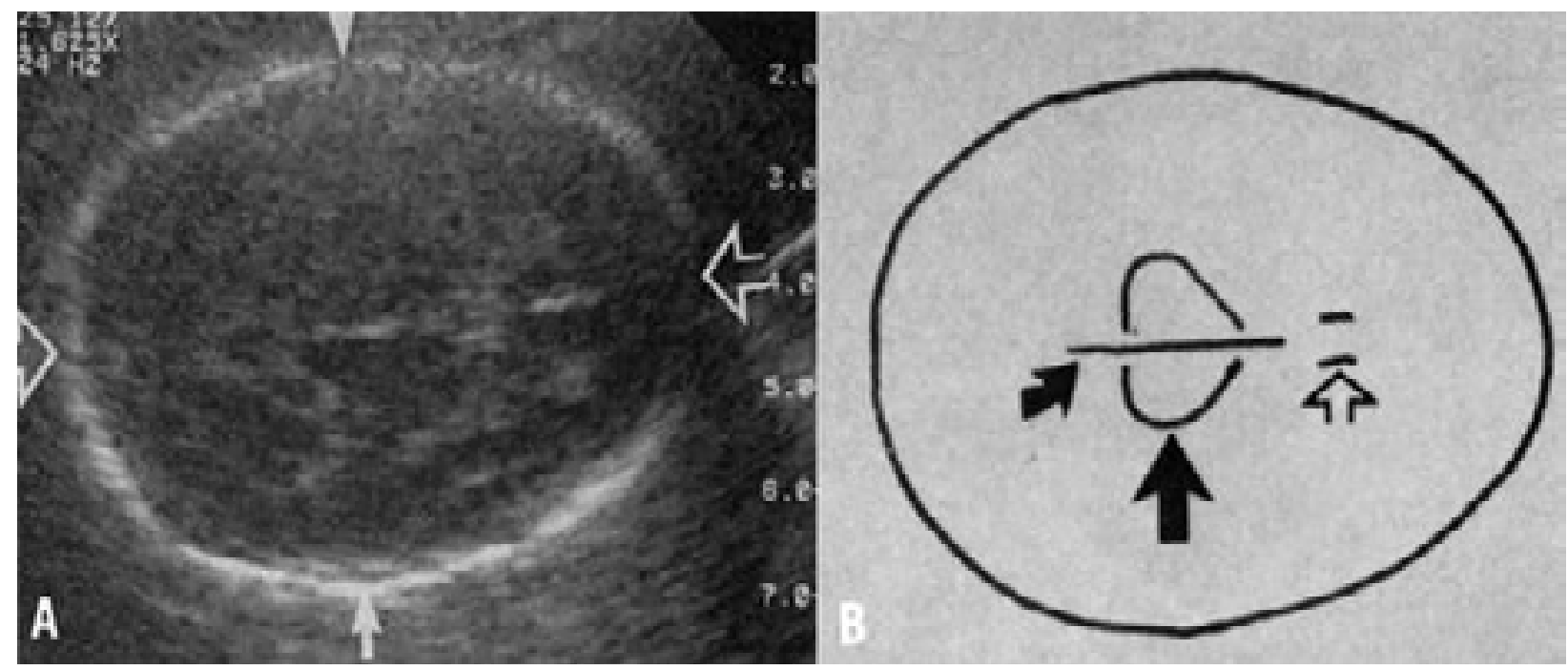

Fig 1. Transverse image of fetal head suitable for BPD, OFD and HC measurements (A) BPD = distance measured at right angle between tips of the solid arrows (depicting outer edge to inner edge approach). Occipito-frontal diameter $(\mathrm{OFD})=$ the distance between the tips of the open arrows. The head circumference was measured by tracing the distance round the skull. (B). Diagram of the transverse image of the fetal skull showing the thalami (large arrow), midline unbroken echo of the falx cerebri (curved arrow), and double echogenic lines (open arrow) of cavum septi pellucidi.

\section{Abdominal circumference}

From a transverse approach, an image of the fetal abdomen showing the fetal liver, stomach, and the left portion of the umbilical vein was captured. ${ }^{5,11}$ AC was then measured by placing the cursor of the track ball at the outermost aspect of the fetal abdomen at the level of the fetal liver and tracing round the fetal abdomen. ${ }^{7,11}$ Measurement of $\mathrm{AC}$ is as shown in figure 2.

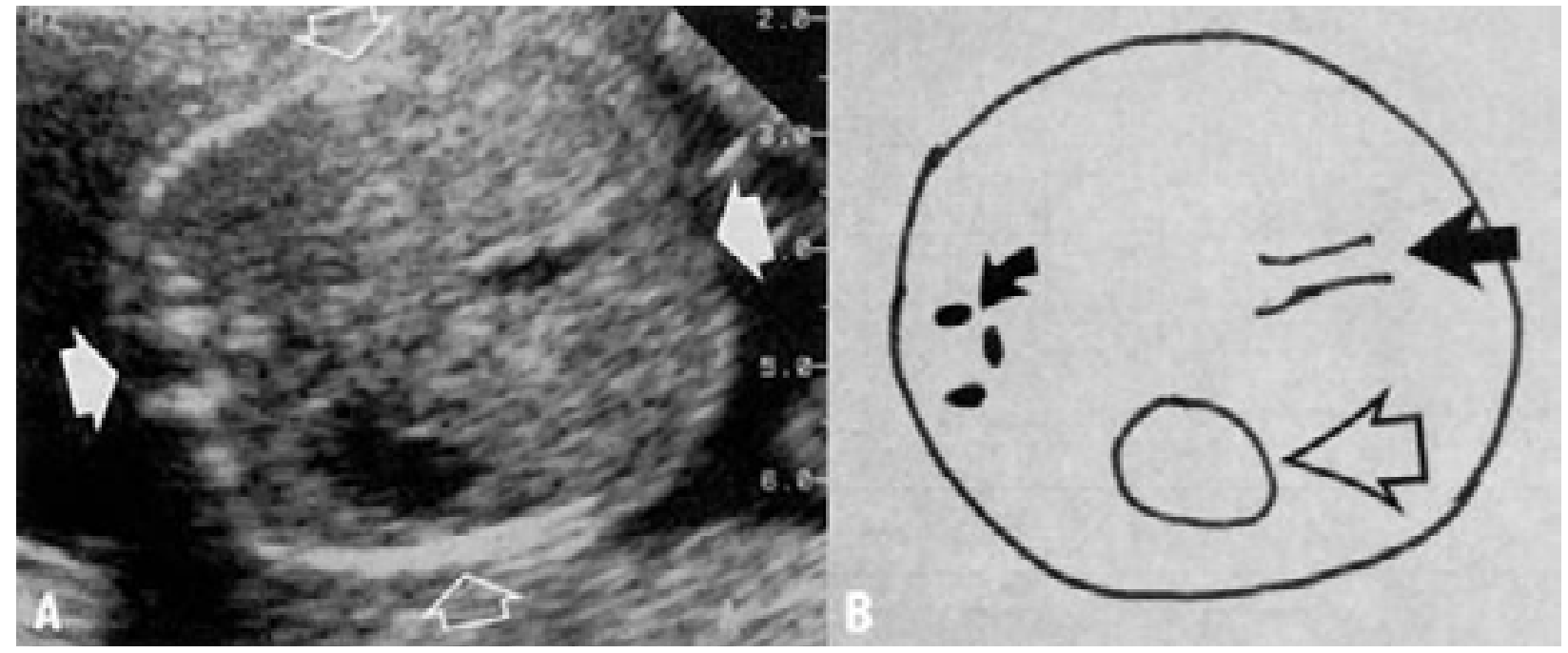

Fig 2. Transverse images of the upper fetal abdomen. A. Solid arrows show movement of the track ball for AC measurement. B. Diagram of the transverse ultrasound image of the fetal abdomen at the level of the abdominal circumference measurement with fetal spine (curved arrow), the umbilical portion of the left portal vein (solid arrow), and fetal stomach (open arrow).

\section{Femur length}

From a transverse section of the fetal abdomen, the transducer was moved caudally till fetal iliac bones were demonstrated at which point a part of the femur was also seen as a bright echo. ${ }^{26}$ From this position, the transducer was rotated till the full length of the femur was demonstrated. Care was taken to ensure that 'soft tissue was visible beyond both ends of the femur and 
that the femoral bone did not merge with the skin of the thigh at any point to enhance the accuracy of FL measurement. ${ }^{26}$ Measurement of FL (measurement of metaphysis) was made by placing the cursor at the center of the U-shape at one end of the femoral bone and tracing it to center of the U-shape at other end. ${ }^{7.26}$ Measurement of FL is shown in figure 3.

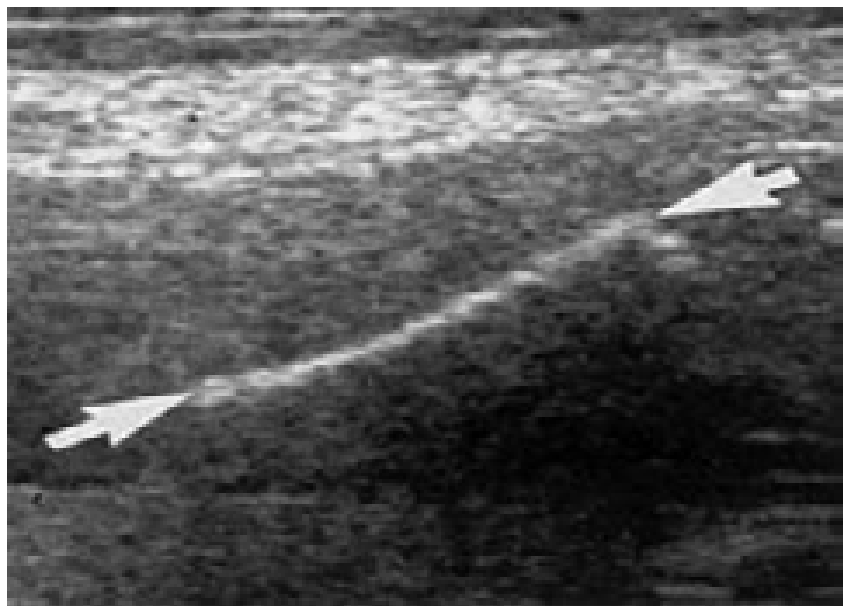

Fig3. An image of fetal femur demonstrating FL measurement

Measurement of FL is best between the U-shapes at each end of the femur.

\section{Sonographic estimated fetal weights (EFWs)}

Each fetal parameter (BPD, HC, AC, and FL) was measured thrice. ${ }^{26}$ After fetal parameters had been measured, the ultrasound scanner automatically calculated the mean of each parameter. With those means, the ultrasound scanner automatically estimated fetal weights. The estimated fetal weights as well as the mean of each fetal parameter were stored in the ultrasound machine's computer memory. After each scanning session, the results stored in the memory were recalled and means of fetal parameters and estimated fetal weights were then copied into a computer flash drive and later transcribed into a computer.

\section{Measurement of actual birth weights (ABW)}

Immediately after delivery, a midwife cleaned the baby with paraffin oil and weighed it on a Crown weighing scale. Babies were weighed before they were fed and within one hour of delivery. ${ }^{27}$ Each naked baby was placed supine on a tray placed in the middle of the Crown weighing scale placed on a sturdy flat table. The movement of the pointer of the weighing scale was observed till it settled and this was read to the nearest
100 grams $^{27}$ and then recorded as the baby's actual birth weight (ABW). Birth weight and sex of each baby were recorded in a data capture sheet. Birth weight was later categorized into microsomic babies $(<2500 \mathrm{~g})$; normal weight babies (2500g-4000g); and macrosomic babies $(>4000 \mathrm{~g}){ }^{28}$

\section{Data analysis}

Both descriptive statistics such as mean, and standard deviation (SD) and inferential statistics such as paired $\mathrm{t}$ test and Pearson's product moment correlation ( $r$ ) were used to interpret results. Furthermore, Bland and Altman plots were used to graphically illustrate the equivalence or difference between EFWs and ABWs. Test for significance of results was set at $\mathrm{p} \leq 0.05$. Analysis was carried out with SPSS computer software, version 17.0. (SPSS Inc., Chicago, Illinois, USA),

\section{Results}

Of the 282 patients studied, table 1 shows that 59 subjects $(21.0 \%)$ were primiparas, $156(55.3 \%)$ were multiparas and $67(23.7 \%)$ were grandparas. This distribution is shown below. 
Table 1. Parity grouping of subjects (pregnant women)

\begin{tabular}{|l|l|}
\hline Parity group & No of pregnant women \\
\hline Primipara & $59(21.0 \%)$ \\
\hline Multi Para & $156(55.3 \%)$ \\
\hline Grand Para & $67(23.7 \%)$ \\
\hline \multicolumn{2}{|c|}{$282(100 \%)$} \\
\hline
\end{tabular}

Table 2 shows that the mean sonographically EFW of fetuses in the population was $3378 \pm 40 \mathrm{~g}$. It (table

2) further shows that sonographically estimated low, normal and excessive weight fetuses were 31 (11.0\%),
$210(74.5 \%)$ and $41(14.5 \%)$ respectively. Furthermore, the mean ABW of fetuses was 3393 $160 \mathrm{~g}$. Also, babies born with low, normal and excessive birth weight were $34(12.1 \%), 205(72.7 \%)$ and $43(15.2 \%)$ respectively. This is shown below.

Table2: Fetal weight categories and percentage of fetuses in each category

\begin{tabular}{|l|l|l|}
\hline \multirow{2}{*}{$\begin{array}{l}\text { Range of fetal } \\
\text { weight }(\mathrm{g})\end{array}$} & \multicolumn{2}{|c|}{ No of fetuses } \\
\cline { 2 - 3 } & Sonographic estimate & $34(12.1 \%)$ \\
\hline $2000-2499$ & $31(11.0 \%)$ & $27(9.6 \%)$ \\
\hline $2500-2999$ & $28(9.9 \%)$ & $84(29.8 \%)$ \\
\hline $3000-3499$ & $87(30.9 \%)$ & $94(33.3 \%)$ \\
\hline $3500-3999$ & $95(33.7 \%) 88$ & $43(15.2 \%)$ \\
\hline $4000-4499$ & $41(14.5 \%)$ & $282(100 \%)$ \\
\hline Total & $282(100 \%)$ & \\
\hline
\end{tabular}

Following sonographic estimation (EFW) and actual weight at birth (ABW), majority of foetuses had normal weight (2500-3999 g).

Table 3: Comparison of estimated fetal weight (EFW) with actual birth weight (ABW)

\begin{tabular}{|l|l|l|l|l|}
\hline Weight category & \multicolumn{1}{|c|}{ EFW (Gram) } & ABW (Gram) & $\begin{array}{l}\text { Coefficient of } \\
\text { correlation (r) }\end{array}$ & P value \\
\hline $\begin{array}{l}\text { Microsomia: } \\
<2500 \mathrm{~g}\end{array}$ & $2285 \pm 35$ & $2289 \pm 37$ & 0.9651 & 0.4863 \\
\hline $\begin{array}{l}\text { Normal weight: } \\
2500-3999\end{array}$ & $3534 \pm 38$ & $3547 \pm 46$ & 0.9475 & 0.4654 \\
\hline $\begin{array}{l}\text { Macrosomia: } \\
>4000 \mathrm{~g}\end{array}$ & $4315 \pm 46$ & $4344 \pm 52$ & 0.8742 & 0.2137 \\
\hline Mean \pm SD & $3378 \pm 40$ & $3393 \pm 45$ & 0.934 & 0.368 \\
\hline
\end{tabular}

SD: Standard Deviation

Strong positive correlation ( $r$ ) existed between EFW and $A B W$ while there was no statistically significant difference between mean estimated and actual birth weight of fetuses for each weight category and in the entire population $(\mathrm{p}>0.05)$. 
Among 43 (15.2\%) babies found with actual excessive birth weight $(>4000 \mathrm{~g})$, table 4 shows that $6(13.9 \%)$ were delivered vaginally (SVD) while 37 (86.1\%) were delivered through caesarian section (CS). Furthermore, a statistically significant difference was found between the number of SVDs and CS deliveries $(p=0.0001)$. This is shown below.

Table 4. Mode of delivery of macrosomic fetuses

\begin{tabular}{|l|l|l|}
\hline Delivery mode & No of macrosomic fetuses & P value \\
\hline $\begin{array}{l}\text { Normal (spontaneous vaginal } \\
\text { delivery[SVD] following induction of } \\
\text { labour }\end{array}$ & $6(13.9 \%)$ & 0.0001 \\
\cline { 1 - 2 } Delivery through Caesarean section (CS) & $37(86.1 \%)$ & \\
\hline \multicolumn{2}{|c|}{ TOTAL $=43(100 \%)$} \\
\hline
\end{tabular}

There was a significant difference between the number of macrosomic fetuses delivered through SVD and the number delivered through CS $(p=0.0001)$.

The mean ABW for primiparas, multiparas and grandparas were $3200 \pm 34 \mathrm{~g}, 3398 \pm 43 \mathrm{~g}$ and $3422 \pm 29 \mathrm{~g}$ respectively (table 5). Table 5 also shows that a significant difference exists in mean ABW of babies born by primiparas and multiparas and between primiparas and grandparas whereas no statistically significant difference was found between those born by multiparas and grandparas.

\section{Table 5. Comparison of mean fetal weights between parity groups}

\begin{tabular}{|l|l|l|l|}
\hline $\begin{array}{l}\text { Parity } \\
\text { Group }\end{array}$ & $\begin{array}{l}\text { Mean fetal weight }(\mathrm{g}) \pm \\
\text { SD }\end{array}$ & $\begin{array}{l}\text { Comparison of mean weight between } \\
\text { parity group }\end{array}$ & P value \\
\hline Primipara & $3200 \pm 34$ & Multipara Versus Primipara & $0.0001^{*}$ \\
\hline Multipara & $3398 \pm 43$ & Grandpara versus Primipara & $0.0001^{*}$ \\
\hline Grandpara & $3422 \pm 29$ & Grandpara versus Multipara & $0.117^{* *}$ \\
\hline
\end{tabular}

*There is statistically significant difference in the mean fetal weights among multipara and Primipara as well between grandparas and primiparas $(\mathrm{p}=0.001)$.

**There is no statistically significant difference between mean fetal weights among grand and multi Para $(\mathrm{p}=0.117)$.

Bland and Altman plot (figure 4) showed strong agreement between EFWs and ABWs because it was only in very few instances that differences between the two fell outside the $95 \%$ limit of agreement. 


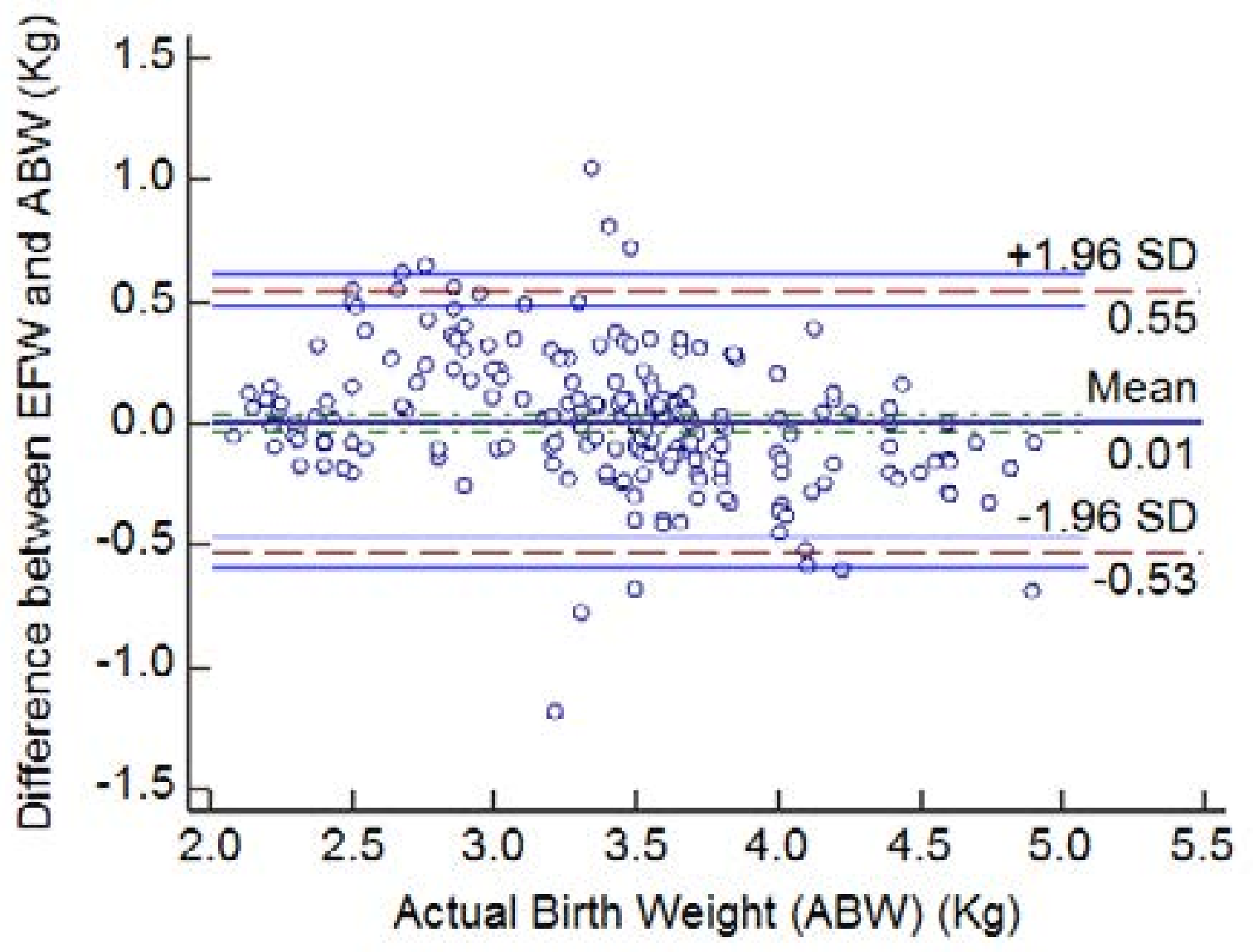

\section{Figure 4: Bland and Altman plots of differences between estimated fetal weight (EFW) and actual birth weight (ABW).}

\section{Discussion}

Nigeria, and indeed, most countries in the sub-Saharan African region are currently having the world's worst maternal and infant mortality rates. ${ }^{1}$ Prediction of pre-natal fetal weight is part of standard antenatal care which helps to reduce maternal risks associated with pregnancy such as prolonged labour, pelvic injuries, postpartum bleeding and pre- and peri-natal fetal risks such as shoulder dystocia and birth asphyxia. ${ }^{6,9}$ Sonography is a well-established imaging modality for pre-natal fetal weight estimation. ${ }^{4,5,20,29}$ Sonography is an easily available and relatively inexpensive imaging modality in Lagos metropolis, Nigeria.

In the study, a majority of women had sonographically estimated fetal weight of fetuses and subsequent actual birth weight within the normal range (normal fetal weight range $=2500 \mathrm{~g}$ to $4000 \mathrm{~g}$; mean $\mathrm{ABW}=$ $3393 \pm 45 \mathrm{~g})$. This result agrees with the range of normal fetal weights earlier reported in literature. ${ }^{30}$ The mean ABW in our study was, however, not significantly different $(\mathrm{p}>0.05)$ from that recorded in an American population but is not the case with Asian and English population $(p<0.05) .{ }^{31,32}$ This result is contrary to what has been reported in literature which had suggested that the birth weight of African babies is generally smaller than that of Caucasian babies. ${ }^{30}$ Our results, however, appear to support the notion that African babies tend to weigh more than Asian babies at birth., ${ }^{40}$ The cause of the differences noted was not investigated in the study. We are, however, inclined to believe that technical limitations such as resolution power of our scanner and observer errors in measurements may have contributed. Furthermore, it is also not unlikely that racial differences may have contributed since it has been reported in literature that racial differences exist in fetal weights. ${ }^{20,21}$ The scan-to-delivery interval (SDI) of 7 days we adopted without adjustment may also have significantly influenced our measurements as it has been reported that fetal weight increases significantly from the $38^{\text {th }}$ week of gestation. . $33,34^{2}$ 
In the study, there was a strong positive correlation between EFW and ABW and there was also no statistically significant difference between mean EFW and mean ABW. For microsomic fetuses and macrosomic babies, we also found no statistically significant difference between EFW and ABW $(\mathrm{p}<0.05)$. Furthermore, no significant difference was found in the number of sonographically predicted macrosomia and the actual number of macrosomic babies. Moreover, there was no statistically significant difference in the number of sonographically predicted low birth weight fetuses and the number of babies born with low birth weights. All this seem to suggest that sonography appears to have accurately predicted fetal weights in this population. Our result, therefore, seems to agree with the opinion of some investigators who reported that the use of Hadlock 3 to sonographically predict fetal was accurate in those populations..$^{23,24,35}$ Since we found no statistically significant difference between sonographically estimated low fetal weight compared with babies actually born with low birth weight, and no statistically significant difference was found between fetuses sonographically predicted with excessive weight compared with babies actually born with excessive weight, our result appears to contrast the notion that sonography may be more accurate at predicting low weight fetuses than it is in predicting excessive weight fetuses. ${ }^{19,36}$.

That we found a statistically significant difference $(p<0.05)$ in the number of excessive weight fetuses delivered vaginally (SVD) and those delivered through Caesarian section (CS) seems an interesting result. In particular, it seems to lay further credence to the fact that the use of the Hadlock 3 fetal weight estimation model was valid in the population and also appears to suggest that the accuracy of sonographically predicted fetal weight in the population was generally high. We cannot explain how or why some macrosomic fetuses were delivered via normal vaginal channel and others were not. We can, however, suggest that sonographically predicted fetal weights may have considerably influenced physicians' opinions in selecting the delivery route in those instances. We can therefore, say with some level of certainty, that our results appear to support earlier ones that reported that sonographic estimation of fetal weight significantly affects the course of obstetric management. ${ }^{10,22,23,35}$

Bland and Altman plot is a graphical method of studying reproducibility and reliability of sonographic meas- urements by comparing such replicate measurements in order to determine their agreement. ${ }^{36}$ In the study,Bland and Altman plots of differences between EFW and ABW showed that only very few cases fell outside the 95\% limits of agreement lines (figure 4). This implies that a high level of agreement exists between EFW and ABW. It can therefore be assumed that sonographically EFWs appear to have truly predicted ABWs in the population. This result agrees with the opinion of previous researchers that sonography is a good estimator of $\mathrm{ABW}$. ${ }^{4,23,24}$

In the study, mean fetal weights appear to have increased as parity increased and as maternal age also increased. In particular, the significant difference $(\mathrm{p}<0.05)$ we found between mean fetal weight among grandparas and primiparas seems to support the opinion of previous investigators who had reported significant differences in fetal weight among different parity groups. ${ }^{37,38}$ We could not establish the cause of such differences in this study but some researchers had earlier attributed them to maternal factors such as increase in age, gait, weight and parity. ${ }^{37,38}$

\section{Limitations}

A major limitation of this study may be the localized nature of the sample studied. The sample was drawn from a population of antenatal clinic attendees in just one tertiary hospital in Lagos, Nigeria (a country with an estimated 170 million people), therefore, the ability to generalize our results is obviously limited. Furthermore, we did not compare sonographic fetal weight estimated with Hadlock 3 algorithm with any other algorithm to determine which algorithm may be more valid in the population. In spite of these limitations, we believe, however, that our result did not establish enough reason to suggest jettisoning ultrasound scanners with Hadlock 3 fetal weight estimation models for sonographic prediction of fetal weight in the population.

\section{Conclusion}

Ultrasonographically estimated fetal weight positively correlated strongly with actual birth weight of fetuses in Lagos metropolis. The use of Hadlock 3 fetal weight estimation model without further validation, therefore, appears to be valid in the population studied. Furthermore, sonography appears to be an accurate predictor of both low and excessive weight fetuses.

We, nevertheless, believe that a further study to compare sonographically estimated fetal weights using different estimation models so as to determine which is best for the Nigerian population may still be necessary. 


\section{Conflict of interest}

None

\section{Acknowledgement}

We wish to sincerely thank the sonographers that helped in data collection. We also wish to express our immense gratitude to the management of the hospital studied for permitting us to carry out this study in their facility.

\section{References}

1. Maya Z. Maternal mortality in Nigeria; an indicator of women's status. Available at http;/ / www.consultancyafrica.com $/$ index.php?option $=$ com_content $\&$ view $=$ article\&id=358\&Itemid=191. Accessed on March 18, 2014 2. CIA World Fact Book 2013. Nigeria infant mortality rate. Available at http;//www.indexmundi.com/Nigeria_infantmortality-rate.html. Accessed on March 19, 2014

3. MacKenzie AP, Stephenson CD, Funai EF. Prenatal sonographic assessment of fetal weight. Available at http;//www.update.com/contents/prenatal-sonographic-assessment-of-fetal-weight. Accessed on March 15, 2014.

4. Shittu AS, Kuti O, Orji EO, Makinde NO, Ogunniyi SO, Ayoola OO, Sule SS. Clinical versus sonographic estimation of fetal weight in southwest Nigeria. J Health Popul Nutr. 2007; 25(1): 14-23. PMID. 17615900

5. Palmer PES. Obstetrics. In: Manual of diagnostic ultrasound. Geneva; World Health Organization. 1995; p236-244.

6. American Pregnancy Association. Cephalopelvic disproportion (CPD). Available at hhtp://americanpregnancy.org/labornbirth/cephalopelvicdisproportion. html. Accessed on March 19, 2014.

7. MacGregor S, Sabbagha R. Assessment of gestational age by ultrasound. Glob.libr.women's med., (ISSN: 1756-2228) 2008. PubMed DOI: 10.3843/ GLOWM.10206.

8. Henriksen T. the macroscopic fetus: a challenge in current obstetrics. Acta Obstet Gynecol Scand. 2008; 87(2): 134-145. Doi: 10.1080/00016340801899289.

9. Nahum GG, Smith CV. Estimation of fetal weight. Available at hhtp://www.emedicine.medscape.com/article/262865-overview. Accessed on February20, 2013 10. Mohammedbeigi A, Farhadifar F, Soufi-zadeh N, Mohammadsalehi N, Rezaiee M, Aghaei M. Fetal macrosomia: risk factors, maternal and perinatal outcome. Ann Med Health Sci Res. 2013; 394): 546-550. DOI. 10.4103/2141-9248.122098
11. Sanders RC, Minner NS. Uncertain dates, elective Caesarian section, late registrants. In: Clinical sonography: a practical guide. Sanders RC, Winter TC III (eds). Philadelphia; Lippincott, Williams and Wilkins 4th ed; 2007, p407-421

12. Predanic M, Pernic S C. Sonographic Assessment of the Umbilical Cord. The Ultrasound review of obstetrics and Gynecology 2005; 4(20):105-110.

13. Hendrix NW, Grady CS, Chauhan SP. Clinical versus sonographic estimates of birth weight in term of parturients: a randomized clinical trial. J Reprod Med. 2000;45;317-322 PubMed . PMID. 10804488

14. Chattergee MS, Izquierdo LA, Nevils B, Gilson GJ, Barada C. fetal foot: evaluation of gestational age. Available at http://www.sonoworld.com/Festus/page. aspx?id=350 Accessed on August 8, 2013.

15. Bossak WS, Spellacy WN. Accuracy of estimating fetal weight by abdominal palpation. J Reprod Med. 1972; 9:58-60 PubMed

16. Ojwang S, Ouko BC. Prediction of fetal weight in utero by fundal height/girth measurements. J Obstet Gynecol East Central Afr. 1984; 3:111

17. Titapant V, Chawanpaiboon S, Mingmitpatanakul K. A comparison of clinical and ultrasound estimation of fetal weight. J Med Assoc Thai. 2001; 84: 1251-1257 PubMed. PMID. 11800297

18. Mehdizadeh A, Alaghehbandan R, Horsan H. Comparison of clinical versus ultrasound estimation of fetal weight. Am J Perinatol. 2000; 17:233-236 PubMed . PMID.11110339

19. Combs CA, Rosenn B, Miodovnik M, SiddiqiTA. Sonographic estimation of fetal weight and macrosomia: is there an optimum formula to predict diabetic fetal macrosomia? J Matern Fetal Med. 2000; 9(1): 55 PubMed -61. PMID. 10757437

20. Hadlock FP, Harrist RB, carpenter RJ, Deter RL, Park SK. Sonographic estimation of fetal weight: the value of femur length in addition to head and abdomen measurement. Radiology. 2004; 150: 535. DOI. 10.1148/ radiology.150.2.6691115

21. Firoozabadi RD, Ghasemi N, Firoozabadi MD. Sonographic fetal weight estimation using femoral length: Honorvar equation. Ann Saudi Med. 2007; 27: 179-182 PubMed. PMID. 17568170

22. Chien PF, Owen P, Khan KS. Validity of ultrasound estimation of fetal weight. Obstet Gynecol. 2000; 95(6 PubMed pt 1): 856-860. PMID. 10831981

23. Venkat A, Chinnaiya A, Gopal M, Monglli JM. Sonographic estimation in a Southeast Asian popula- 
tion. J Obstet Gynaecol Res. 2001; 27(5): 275-279. PMID. 11776510

24. Kurmanavicus J, Burkhardt T, wiser J, Huch R. Ultrasonographic fetal weight estimation: accuracy of formulas and accuracy of examiners by weight from 500 to 5000g. J Perinat Med. 2004; 32(2): 155 PubMed -161. PMID. 15085892

25. Ibukun, AO, Olatona FA, Oridota ES, Okafor IP, Onajole AT. Knowledge and uptake of community-based health insurance scheme among residents of Olwora, Lagos. Journal of Clinical Sciences 2013; 10(2): 8-12.

26. Chudleigh P, Pearce JM. Obstetric ultrasound: how, why and when. Edinburgh; UK: Churchill Livingstone (Medical division of Longman Group UK LTD); 1986; pp. 49-60.

27. Raman S, Urquhart R, Yusof M. Clinical versus ultrasound estimation of fetal weight. Aust N Z J Obstet Gynaecol. 2005; 32:196-199. PMID. 1445124

28.Estimation of fetal weight. Available at http:// www.scribd.com/doc/26799656/Estimation-of-Fetal-Weight. Accessed on March 17, 2014.

29. Nzeh DA, Oyawoye O, Adetoro OO. Ultrasound estimation of birth weight in late pregnancy among African women. West African J Ultrasound. 2000;1:9-14

30. Glenn E (ed). Mass of a newborn baby. In: The physics Factbook. Available at http://hypertextbook. com/facts/2002/LeahOppenheim1.shtml. Accessed on March 12, 2014.
31.Ianneli V. Baby weight statistics. Available at pediatrics.about.com/od/growthanddevelopment/a/babybirth-weight.htm. Accessed on March 3, 2013.

32. Baby weight Available at www.cgbabyclub.co.uk/article/baby-weight. Accessed on March 3, 2013.

33. Cohen JM, Hutcheon JA, Kramer MS, Joseph KS, Abenhaim H, Platt RW. Influence of ultrasound-to-delivery-interval and maternal-fetal characteristics on validity of estimated fetal weight. Ultrasound Obstet Gynecol. 2010; 35(4): 434-441. Doi: 10.1002/uog.7560

34. Nahum GG, Stanislaw H. Ultrasonographic prediction of term birth weight: how accurate is it? $A m \mathrm{~J}$ Obstet Gynecol. 2003; 188(2):566 PubMed -576. PMID. 12592273

35. Coomarasamy A, Coonock M, Thornton J, Khan KS. Accuracy of ultrasound biometry in the prediction of macrosomia: a systematic quantitative review. BJOG. 2005; 17(11): 1461 PubMed -1466. PMID. 16225563

36. Bland JM, Altman DG. Measuring agreement in method comparison studies. Statistical Methods Med Res 1999; 8: 135-160. PMID. 10501650

37. Barel O, Maymon R, Vakin Z, Tovbin J, Smorgick $\mathrm{N}$. Sonographic fetal weight estimation-is there more to it than just measurements? Prenatal diagnosis. 2014; 34(1); 50 PubMed -54. DOI: 10.1002/pd.4250.

38. Dudley NJ. A systematic review of theultrasound estimation of fetal weight. Ultrasound Obstet Gynecol. 2005; 25(1); 80-89 PMID:15505877 